\title{
MANFAAT PENDIDIKAN KEWARGANEGARAAN PADA ANAK SEKOLAH DASAR
}

\author{
Fahrid Maruf Alfiyana \& Dinie Anggareni Dewi \\ Universitas Pendidikan Indonesia \\ fahridmaruf@upi.edu
}

\begin{abstract}
Abstrak
Tujuan penelitian ini yaitu untuk mengetahaui apa saja manfaat Pendidikan kewarganegaraan bagi anak.. Penelitian ini berlatarkan dari rasa keingintahuan penulis mengenai apa saja manfaat Pendidikan kewarganegaraan bagi anak menurut anak sekolah dasar itu sendiri. Metode Penelitian ini menggunakan jenis penelitian kualitatif, dimana peneliti secara langsung menanyakan informasi kepada anak-anak sekolah dasar. Hasil penelitian menunjukan bahwa rata-rata anak sekolah dasar menjawab Pendidikan kewarganegaraan sangat bermanfaat bagi mereka, terlebih untuk meningkatkan rasa cinta tanah air diri mereka.
\end{abstract}

Kata kunci: Pendidikan Kewarganegaraan, Manfaat, Anak Sekolah Dasar

\begin{abstract}
The purpose of this research is to find out what are benefits of civic education for children. This research is based on the writer curiosity about the what are the benefits of civic education for children according to elementary school children. This research method uses a type of qualitative research in which researchers directly ask information to elementary school children. The result showed that the average distance between elementary school children answer civic education is very beneficial for them, especially to increase their love for their homeland.
\end{abstract}

Keyword: Civic Education, Benefit, Elementary School Children

\section{PENDAHULUAN}

Pada dasarnya, pendidikan memiliki tujuan untuk membangun karakter siswa (Aisy \& Nurani, 2016). Tujuan yang diinginkan pada pendidikan berada pada Undang- undang Nomor 20 Tahun 2003 mengenai Sistem Pendidikan Nasional pada pasal 3 yang isinya: "Pendidikan nasional berfungsi mengembangkan dan membentuk watak dan peradaban bangsa yang bermartabat dalam rangka mencerdaskan kehidupan bangsa, bertujuan untuk berkembangnya potensi peserta didik agar menjadi manusia yang beriman dan bertakwa kepada Tuhan Yang Maha Esa, berakhlak mulia, sehat, berilmu, cakap, kreatif, mandiri, dan menjadi warga negara yang demokratis serta bertanggung jawab."

Melalui Kementerian Pendidikan dan Kebudayaan Republik Indonesia, pemerintah telah merencanakan penerapan pendidikan karakter untuk seluruh taraf pendidikan dari SD sampai Perguruan Tinggi (Bahrudin, 2019). Pendidikan karakter penting karena apabila karakter telah terbentuk di usia dini maka akan gampang untuk mengubah karakter seseorang di masa yang akan datang (Hanifa \& Dewi, 2021). Ia pun menginginkan pendidikan karakter dapat menciptakan kepribadian bangsa.

Banyaknya tindakan tidak bermoral yang dilakukan siswa seperti mencontek, tawuran, membolos dan tindakan lainnya menandakan bahwa pendidikan formal gagal membentuk karakter peserta didik (Yunita \& Suryadi, 2018). Pendidikan Kewarganegaraan merupakan salah satu konsep pendidikan yang berfungsi untuk membentuk siswa sebagai warga negara yang mempunyai karakter.

Pendidikan

Kewarganegaraan dijadikan sebuah bahan dalam 
pembelajaran Pendidikan yaitu Pancasila dan kewarganegaraan. Belajar tentang Pendidikan Kewarganegaran pada dasarnya adalah belajar mengenai keIndonesia-an, belajar untuk menjadi warga negara yang berkepribadian Indonesia tentunya sesuai dengan Pancasila, membangun rasa kebangsaan dan juga menumbuhkan rasa cinta tanah air Indonesia. Anak sekolah dasar adalah seorang anak yang berusia 6-12 tahun yang sedang menempuh Pendidikan di suatu instansi Pendidikan dasar (Nurgiansah, 2021).

\section{METODE PENELITIAN}

Penelitian yang dilakukan menggunakan jenis penelitian kualitatif, yaitu penelitian yang bertujuan untuk meneliti dan menemukan informasi sebanyak-banyaknya melalui wawancara. Wawancara adalah percakapan antara dua orang atau lebih yang berperan sebagai narasumber dan pewawancara. Wawancara tersebut akan menghasilkan data-data. Data yang didapatkan akan dijadikan dalam uraian naratif, sehingga dapat mengambarkan keadaan yang dimaksud. Penelitian ini ditujukan pada beberapa anak sekolah dasar, dengan pencarian informasi yang dilakukan pada tanggal 10 April melalui wawancara secara langsung dengan tetap menerapkan protokol kesehatan yang berlaku. Adapun narasumber dari wawancara ini sebanyak 10 orang, yang terdiri dari 3 orang laki-laki dan juga 7 orang perempuan.

\section{HASIL PENELITIAN DAN PEMBAHASAN Hasil Penelitian}

Penelitian yang dilakukan penulis melalui wawancara secara langsung pada beberapa anak sekolah dasar, mengenai apa manfaat Pendidikan kewarganegaraan bagi mereka sebagai siswa dan siswi sekolah dasar, diperoleh hasil sebagai berikut:
1. Apa arti Pendidikan kewarganegaraan bagi kalian?

Enam dari 10 anak menjawab Pendidikan Kewarganegaraan adalah Pendidikan yang mendidik bagaimana mereka menjadi warga negara yang baik, sedangkan sisanya menjawab bahwa Pendidikan kewarganegaraan adalah Pendidikan yang sangat formal dan penting bagi anak.

2. Apa manfaat Pendidikan kewarganegaraan menurut kalian?

Sepuluh dari $\begin{array}{r}\text { Sepuluh anak } \\ \text { menjawab }\end{array}$
Pendidikan
Kewarganegaraan sangat penting bagi mereka, terlebih manfaat Pendidikan kewarganegaraan bagi mereka juga cukup banyak. Seperti menumbuhkan rasa cinta tanah air mereka terhadap negara, meningkatkan rasa bela negara yang ada pada diri mereka, dan lain sebagainya.

\section{Pembahasan}

Pendidikan Kewarganegaraan adalah mata pelajaran yang penting yang harus diajarkan kepada anak. Dengan Pendidikan kewarganegaraan, anak akan dituntut untuk memiliki rasa cinta tanah air dan memiliki karakter kebangsaan yang mumpuni (Nurgiansah, 2020). Kita sebagai pendidik baik itu guru disekolah maupun orang tua di rumah harus bisa menanamkan Pendidikan kewarganegaraan kepada anak sedini mungkin, karena hal tersebut penting untuk membentuk pribadi anak sebagai generasi penerus bangsa yang baik. Karena pada akhirnya, anak-anak juga akan terjun ke masyarakat secara langsung yang mana secara otomatis mereka harus sudah paham akan nilai-nilai Pancasila dan mengaplikasikannya dengan baik.

Selain itu juga, anak-anak sebagai generasi penerus ini harus bisa menjaga Pancasila dan UUD 1945 sebagai dasar negara Indonesia. 
$\begin{array}{lllr}\text { Maka dari } & \text { itu, } & \text { pendidikan } \\ \text { kewarganegaraan } & \text { sangat } & \text { penting }\end{array}$ disampaikan sejak dini kepada anak-anak kita. Selain sekolah, keluarga juga harus ikut serta dalam mendidik karakter dan kesadaran anak akan pendidikan kewarganegaraan. Dengan begitu, kita bisa menghasilkan calon-calon generasi bangsa yang baik dan yang bisa membuat Indonesia menjadi negara yang lebih baik lagi (Dewantara \& Nurgiansah, 2021).

\section{KESIMPULAN}

Pendidikan

kewarganegaraan

sangatlah bermanfaat bagi anak anak sekolah dasar, karena dengan Pendidikan kewarganegaraan anak bisa menjadi pribadi yang memiliki rasa cinta tanah air yang tinggi dan mampu untuk membela tanah air sepenuh hatinya. Bagi orang tua harus sering mengingatkan dan mengajarkan anak mengenai Pendidikan kewarganegaraan dan bagaimana cara menjadi masyarakat yang berbangsa dan bernegara kepada anak. Bagi tenaga pengajar seperti guru, harus bisa memaksimalkan asupan Pendidikan kewarganegaraan kepada anak demi terciptanya Negara Kesatuan Republik Indonesia yang maju.

\section{DAFTAR PUSTAKA}

Aisy, K. V. R., \& Nurani, F. (2016). Melihat sejarah nasionalisme Indonesia untuk memupuk sikap kebangsaan generasi muda. Jurnal Civics: Media Kajian Kewarganegaraan, 13(2), 209-216. https://doi.org/10.21831/civics.v13i2.12745

Bahrudin, F. A. (2019). Implementasi Kompetensi Mata Kuliah Pendidikan Kewarganegaraan Di Perguruan Tinggi Dalam Menghadapi Tantangan Globalisasi. Pro Patria: Jurnal Pendidikan, Kewarganegaraan, Hukum, Sosial, Dan Politik, 2(2), 184-200. https://doi.org/10.47080/propatria.v2i2.593

Dewantara, J. A., \& Nurgiansah, T. H. (2021). Building Tolerance Attitudes Of PPKN Students Through Multicultural Education Courses. Jurnal Etika Demokrasi, 6(1), 103-115.

Hanifa, S., \& Dewi, D. A. (2021). Kesadaran Patriotik Di Kalangan Mahasiswa. Jurnal Pendidikan Indonesia, 2(4), 757-763.

Nurgiansah, T. H. (2020). Filsafat Pendidikan. In Banyumas: CV Pena Persada.

Nurgiansah, T. H. (2021). Pendidikan Pancasila. In Solok: CV Mitra Cendekia Media.

Yunita, Y., \& Suryadi, K. (2018). Rancang Bangun Pendidikan Bela Negara Sebagai Wahana Pengembangan Sikap Nasionalisme Bagi Mahasiswa. MODELING: Jurnal Program Studi PGMI, 5(2), 225-233. 